\title{
A Comparative Study of the Heavy Metals in the Meat of Chickens in Different Cities of Pakistan. A Review
}

\author{
Abdul Hakeem, Naqeebullah Khan*, Attiq-ur-Rehman, Samiullah Khan \\ Department of Chemistry, University of Baluchistan, Quetta 87300-Pakistan
}

\begin{tabular}{ll}
\hline Articles Information & Abstract \\
\hline Received: & The quality of food stuff is the main concern of everyone and scientific \\
04.11 .2019 & community is busy in monitoring and ensuring the quality. The aim of this \\
Accepted: & review is study the importance of heavy metals in and the concentrations of \\
31.12 .2019 & these in the meat of chickens. The data of heavy metals concentration $(\mathrm{Pb}, \mathrm{Cd}$, \\
Published: & Zn, Cu, Ni) in chicken meat determined in various cities of Pakistan such as \\
04.06 .2020 & Karachi, Kohat, Lahore and Kasur city is presented in this review and a \\
& comparison study is conducted among the results. The mean accumulation of \\
& lead was observed the highest in the research study performed in Lahore of four \\
& cities of Pakistan due to the lead contaminated chicken food while that of \\
& Karachi was observed the lowest mean level of Pb of all. Kohat was found second \\
& to all. The mean concentration of cadmium was observed the highest level in \\
Keywords: & Kohat, because the main source of cadmium is food, among all concerned cities \\
of Pakistan. The research study in Karachi was observed the lowest amount of \\
Heavy metals & cadmium in liver. However, no any significant difference of Cd in liver between \\
Concentration & Lahore and Kasur was observed. The mean concentration of Zn was observed \\
Pakistan & the highest in the liver of Lahore as source of the metals are chicken food than \\
& other studies compared. The mean levels of zinc in study of Karachi were \\
& observed the lowest of all. On the other hand, the mean accumulation of nickel \\
& was observed highest in Karachi due to the industrial wastes that contaminate \\
the chicken food, among the already performed studies of all three cities while & Kohat study result was observed the lowest mean concentration of nickel among \\
&
\end{tabular}

DOI: 10.22401/ANJS.23.2.11

* Corresponding author: naqeebhmd2@gmail.com

\section{Introduction}

Heavy metals term is used for the metals that have greater density relative to other metals in the periodic table and are very poisonous even at minute amount [1]. This term is used collectively to the metals that have greater density than water $(4 \mathrm{~g} / \mathrm{cm} 3)$ [2]. These can't be decayed by the action of livings things and can assemble in the body of living things and become the cause of many diseases and chaos [3]. Heavy metals are source of pollution in various things such as food, water, soil etc. These enter in the water, soil and food from the waste of industries, mining dryers etc. [4]. Human food consists of vegetables, animals and birds. The very cheap protein source for human is chicken. Chicken meat is used globally to resolve the food problems and to meet other necessary nutrients such as fat, protein, minerals and vitamins to human beings [5]. Heavy metals make an entrance to chickens through feeds [6]. The accumulation of heavy metals in the chickens impacts them by various actions [7]. Chickens are mostly vulnerable to heavy metals by several means like sewage water, chicken feed, polluted water, industrial discharges and also via airy sprays in hen's upbringing regions [8]. One more factor that greatly pollute the meat which is retailed, generally, in exposed marketplaces and occasionally on footpaths [9]. These become responsible for the disease in human $[10,11]$. The infested birds may become the cause of numerous lethal infections to human in Pakistan [12]. The large amount of heavy metals becomes dangerous to the living things [13]. The presence even, a little amount of heavy metals is a great danger to the human health and food safety due to their toxic nature [14]. Chickens are highly susceptible to the heavy metal intoxication, especially the cadmium as it penetrates by feeding on the plant origin food. Its accumulation in body leads to renal failure, osteoporosis and mutagenic effects beyond the threshold limits established by the WHO. Copper 


\section{Al-Nahrain Journal of Science}

ANJS, Vol.23 (2), June, 2020, pp. 75 - 79

metal is essential element for the maintenance of body homeostasis as well act as cofactor in many enzymatic activities inside the body [15]. Chromium plays role in catabolism of protein, sugar, and fat but its excess lead to cancer [16]. It is considered that chicken meat and its products contain some trace heavy metals and thus, exposure to the trace heavy metals will be obtained through intake of these products, the accurate determination of them has been focused by researchers in last decades, worldwide [17, 18]. The results of already performed research studies. The augmentation of some weighty metals in the livers and muscles of chicken were reviewed from other research studies already performed in different cities of Pakistan. Table 1 shows the mean concentration in liver and muscles of chicken in Karachi. This research study has been performed in Karachi by Zaheer khan and his colleagues [19]. This study was done with help of atomic absorption spectrometry. Table 2 indicates the mean level of some heavy metals in the liver and meat of chicken. This analysis on concentration of heavy metals has been conducted in Kohat by Abd EI-Salam and others through atomic absorption spectrophotometer [20]. Table 3 shows the concentration of weighty metals in the liver and muscles of chicken. Irfana Mariam and her colleagues performed analysis on concentration of some heavy metals in Lahore [21]. and table 4 indicates the mean concentration of weighty metals in liver and muscles of chicken. Imran and his friends have performed this research study in Kasur city and they have used Couple PlasmaSpectrophotometer [22].

Table 1. The mean accumulation of heavy metals in chickens at Karachi (ppm).

\begin{tabular}{llllll}
\hline Organs & $\mathrm{Pb}$ & $\mathbf{C d}$ & $\mathrm{Zn}$ & $\mathbf{C u}$ & $\mathrm{Ni}$ \\
\hline Liver & 0.339 & 0.103 & 8.39 & 1.53 & 6.16 \\
Meat & 1.797 & 0.366 & 6.41 & 0.363 & 4.13 \\
Blood & 0.239 & 0.009 & 3.361 & 0.496 & 0.277 \\
\hline
\end{tabular}

Table 2. The mean accumulation of heavy metals in chicken in Kohat (ppm).

\begin{tabular}{llllll}
\hline Organs & $\mathrm{Pb}$ & $\mathrm{Cd}$ & $\mathrm{Zn}$ & $\mathrm{Cu}$ & $\mathrm{Ni}$ \\
\hline Liver & 2.9 & 1.213 & 19.95 & 20.863 & 0.25 \\
Meat & 2.275 & 1.15 & 7.4 & 2.5 & 0.25 \\
Heart & 2.388 & 0.875 & 16.138 & 0.413 & 0.213 \\
Pancreas & 1.95 & 1.513 & 14.025 & 4.8 & 2.238 \\
\hline
\end{tabular}

Table 3. The mean augmentation of heavy metals of chicken in Lahore (ppm).

\begin{tabular}{llllll}
\hline Organs & $\mathbf{P b}$ & $\mathbf{C d}$ & $\mathbf{Z n}$ & $\mathbf{C u}$ & $\mathrm{Ni}$ \\
\hline Liver & 3.15 & 0.49 & 54.53 & 6.91 & - \\
Meat & 3.1 & 0.31 & 28.52 & 12.86 & - \\
\hline
\end{tabular}

Table 4. The mean concentration of heavy metals in chicken in Kasur (ppm).

\begin{tabular}{llllll}
\hline Organs & $\mathrm{Pb}$ & $\mathrm{Cd}$ & $\mathrm{Zn}$ & $\mathrm{Cu}$ & $\mathrm{Ni}$ \\
\hline Liver & 2.29 & 0.50 & 31.89 & 2.78 & 3.88 \\
Meat & 2.35 & 0.35 & 30.93 & 2.38 & 2.78 \\
Heart & 2.25 & 0.45 & 33.02 & 3.01 & 3.49 \\
Kidney & 2.42 & 0.40 & 33.42 & 2.23 & 3.00 \\
\hline
\end{tabular}

\section{Comparative study}

The mean level of lead was observed highest in both liver and meat of chicken in the result of research already conducted in Lahore as compared to Karachi, Kohat and Kasur. Whereas, the lead mean concentration in liver of chicken in Kohat study was observed lower than Lahore but higher than Karachi and Kasur. On the other hand, the mean level of lead in the meat of chicken in Kohat was noticed lower than Lahore and higher than Karachi but no any momentous dissimilarity was observed between Kohat and Kasur. The mean concentration of $\mathrm{Pb}$ in the liver and muscles of chicken in Karachi are lowest of all mentioned areas. The organ heart was studied only in Kohat and Kasur city. In the level of lead was not observed any significant difference. Blood was studied only in Karachi and kidney was studied only in Kasur and pancreas was studied only in Kohat (Figure 1).

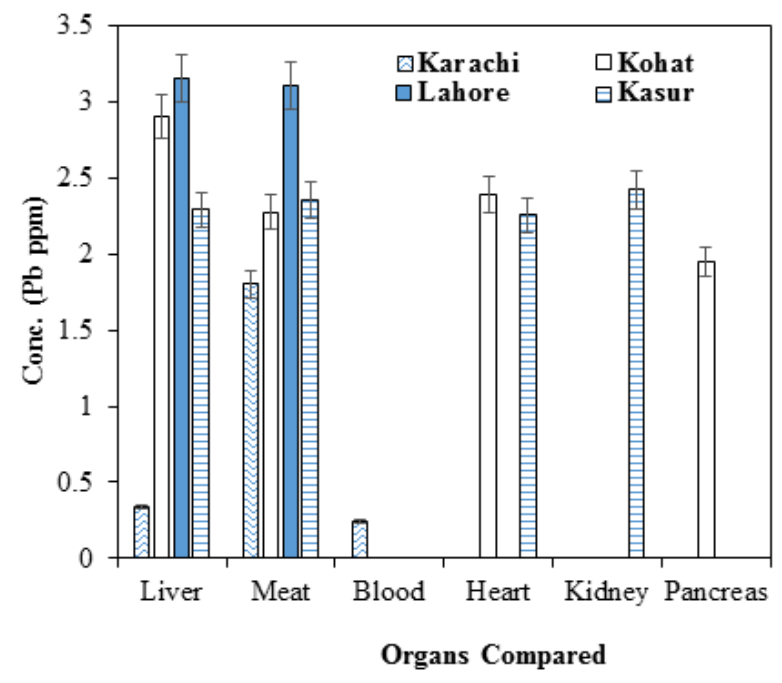

Figure 1. Comparison of the mean accumulation of $\mathrm{Pb}$ in some organs of chickens among various cities of Pakistan. 


\title{
Al-Nahrain Journal of Science
}

\author{
ANJS, Vol.23 (2), June, 2020, pp. 75 - 79
}

The mean level of cadmium was observed highest in both liver and meat of chicken in the result of research already conducted in Kohat as compared to Karachi, Lahore and Kasur. But no any significant difference was observed between the research study of Lahore and Kasur city for the liver of chicken. Whereas, the mean concentration of cadmium in liver of chicken of these both cities was higher than the Karachi research study. Conversely, the mean level of $\mathrm{Cd}$ in the meat of chicken of Karachi and Kasur was not observed any significant difference. But in turn, mean level of $\mathrm{Cd}$ in meat of these both was a little bit higher than Lahore chicken. The level of $\mathrm{Cd}$ in heart of Kohat was found greater than Kasur while it was not studied in other two cities (Figure 2).

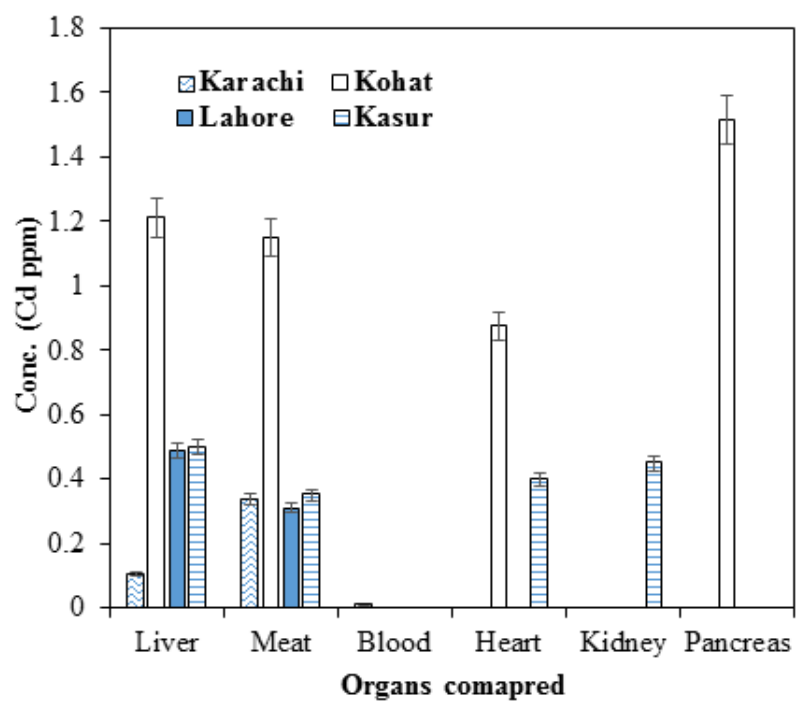

Figure 2. Comparison of the mean accumulation of $\mathrm{Cd}$ in some organs of chickens among various cities of Pakistan.

The Lahore chicken liver contained the highest mean concentration of zinc among all four cities and that of Karachi chicken liver had the lowest mean amount of zinc among all concerned cities. On the other hand, liver of Kasur chicken had lower level of Zn than Lahore but higher than the accumulation of $\mathrm{Zn}$ in the livers of Kohat and Karachi chickens. Similarly, the muscles of Kasur hen were having the highest mean quantity of zinc among all four cities of Pakistan and that of the meat of Lahore chicken was lower than Kasur but higher than the concentration of $\mathrm{Zn}$ in the meat of Kohat and Karachi chickens. However, the mean level of zinc in muscles of chickens of Kohat was little higher than the muscles of Karachi chickens. The heart of Kasur chicken was found with greater quantity than the heart of Kohat chicken.
Whereas, other two cities were not studied for heart sample (Figure 3).

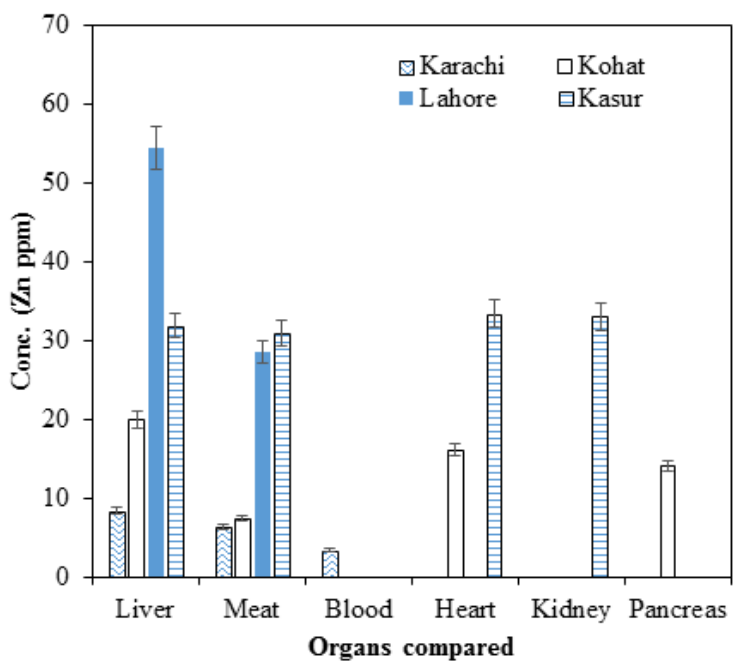

Figure 3. Comparison of the mean accumulation of $\mathrm{Zn}$ in some organs of chickens among various cities of Pakistan.

The mean level of copper in liver of Kohat chicken was higher than other three. On the other hand, the level of copper in the liver of Lahore chicken was lower than Kohat but higher than the accumulation of $\mathrm{Cu}$ in the livers of Karachi and Kasur chickens. Comparatively, the Kasur chicken liver had higher concentration of $\mathrm{Cu}$ than Karachi chicken liver. Similarly, the concentration of copper in the meat of chicken of Lahore was observed high as compared to Karachi, Kasur and Kohat chicken meat. While, the meat of Kasur and Kohat did not show any significant difference in the quantity of $\mathrm{Cu}$. However, the lowest level of copper was observed in the muscles of Karachi chicken. The level of copper was found greater in the heart of Kohat chicken but other two cities were studied for heart sample (Figure 4).

The mean accumulation of nickel in the chicken liver of research performed in Karachi was observed higher than the level of $\mathrm{Ni}$ in the chicken liver of research study done in Kasur which in turn was higher than the level of $\mathrm{Ni}$ in chicken liver of Kohat. Similarly, the level of nickel in the meat of Karachi chicken was greater than the meat of Kasur chicken which in turn was greater than the level in the meat of Kohat chicken. The level of nickel the heart sample of Kasur was observed greater than Kohat sample and rest of the cities were not considered for heart samples (Figure 5). 


\section{Al-Nahrain Journal of Science}

ANJS, Vol.23 (2), June, 2020, pp. 75 - 79

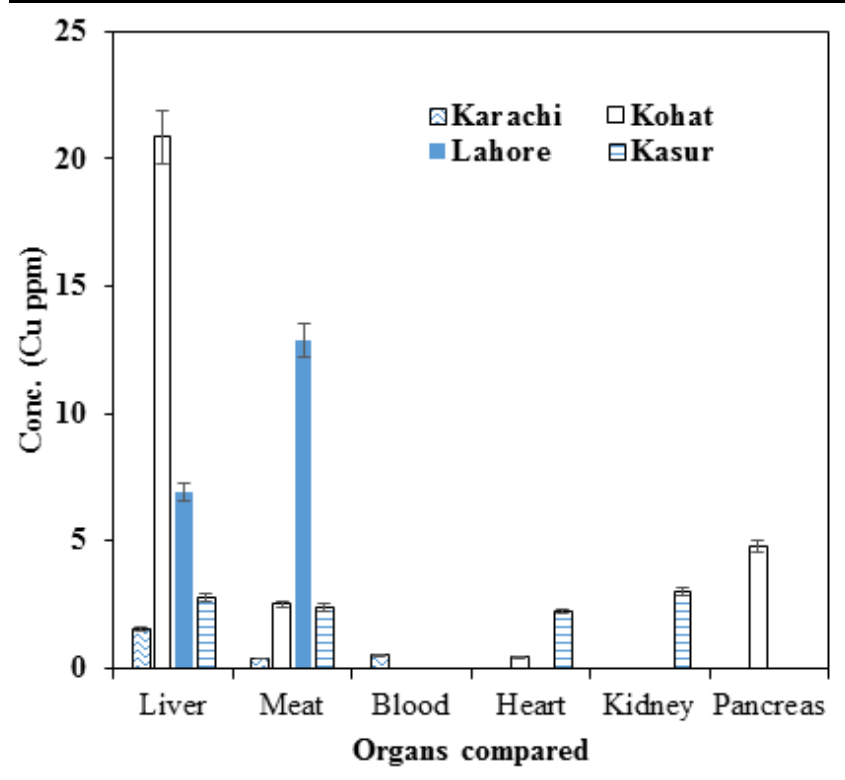

Figure 4. Comparison of the mean accumulation of $\mathrm{Cu}$ in some organs of chickens among various cities of Pakistan.

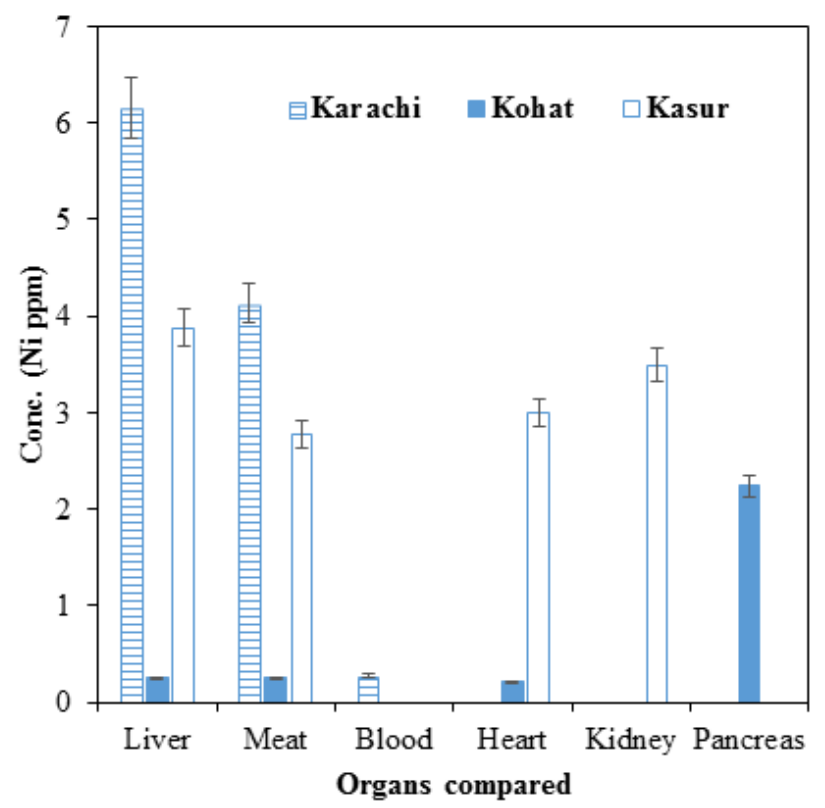

Figure 5. Comparison of the mean accumulation of $\mathrm{Ni}$ in some body parts of chickens among various cities of Pakistan.

\section{Conclusions}

The mean accumulation of $\mathrm{Pb}$ was observed higher in both liver and meat of chicken of the research study in Lahore than other concerned cities of Pakistan while that of Karachi study was observed the lowest level of $\mathrm{Pb}$ as compared to other research studies. The Kohat study showed higher level of $\mathrm{Pb}$ in liver then Karachi and Kasur but in meat no any difference was observed between
Karachi and Kohat. The mean concentration of cadmium was observed the highest in Kohat among the already performed studies in concerned cities of Pakistan. The research study in Karachi was observed the lowest level of $\mathrm{Cd}$ in meat while no any significant difference was observed between Karachi and Kasur. However, level of $\mathrm{Cd}$ in meat of Lahore was observed lowest of all. The mean concentration of $\mathrm{Zn}$ was observed higher in the liver of Lahore than other while Kasur was lower than Lahore but higher than Karachi and Kohat. The level of Cd in the meat of Kasur was higher than Lahore which in turn greater than Karachi and Kohat. However, no any difference was observed between the research studies of Kohat and Karachi. Highest $\mathrm{Cu}$ level was observed in the liver of Kohat while in the meat of Lahore. The level of Lahore was greater than Kasur which in turn was greater than Karachi while in meat of Karachi and Kasur was no any difference. On the other hand, nickel concentration was observed highest in Karachi among all three cities while Kohat study on chicken was observed the lowest concentration of nickel among the three.

\section{Acknowledgement}

The authors are extremely grateful to Department of Chemistry, University of Baluchistan, Quetta Pakistan and authors acknowledged and express their gratefulness to a great assistance from side of University

\section{References}

[1] Alloway, B. J.; "Heavy metals in soils: trace metals and metalloids in soils and their bioavailability"; Springer Science \& Business Media 22, 2012.

[2] Khan, H.; Khan, S.; Khan, N.; Ali, I.; Achakzai, A. B.; "Physicochemical and Spectroscopic Elemental Analysis of Ground Water in Thickly Populated and Industrial Area of Quetta Valley Pakistan"; AlNahrain Journal of Science, 22, 18-25, 2019.

[3] Giri, S.; Singh, A. K.; "Heavy metals in eggs and chicken and the associated human health risk assessment in the mining areas of Singhbhum copper belt, India"; Arch. Environ. Occup. Health 74, 161-170, 2019.

[4] Habib, H. R.; Awadh, S. M.; Muslim, M. Z.; "Toxic heavy metals in soil and some plants in Baghdad, Iraq"; Al-Nahrain J. Sci. 15, 1-16, 2012.

[5] Alturiqi, A.S.; Albedair, L.A.; "Evaluation of some heavy metals in certain fish, meat and meat products in Saudi Arabian markets"; The Egy. J. Aqua. Res. 38, 45-49, 2012.

[6] Kim, D.; Hwang, S. J.; Kim, Y.; Jeong, C. H.; Hong, Y. P.; Ryoo, K. S.; "Removal of Heavy Metals from Water Using Chicken Egg Shell Powder as a BioAdsorbent”; Bull. Kor. Chem. Soc. 2019. 


\section{Al-Nahrain Journal of Science}

ANJS, Vol.23 (2), June, 2020, pp. 75 - 79

[7] Elawady, E. F.; El Bayomi, R. M.; "Risk Assessment of some Heavy Metals from Claris gariepinus Consumed in Sharkia Governorate, Egypt"; Zagazig Veter. J. 47, 193-202, 2019.

[8] Morshdy, A. E. M.; El Bayomi, R. M.; El Galil, G. M. A.; Mahmoud, A. F.; "Heavy Metal Concentrations and Their Risk Assessment in Marketed Slaughtered Animals in Sharkia Governorate, Egypt"; Veterinary Medicine Inbetween Health \& Economy 55, 2018.

[9] Li, Y.; McCrory, D. F.; Powell, J. M.; Saam, H.; Jackson-Smith, D.; "A survey of selected heavy metal concentrations in Wisconsin dairy feeds"; J. Dai. Sci. 88, 2911-2922, 2005.

[10] Santhi, D.; Balakrishnan, V.; Kalaikannan, A.; Radhakrishnan, K.T.; "Presence of heavy metals in pork products in Chennai (India)"; Am. J. Food Technol, 3, 192-199, 2008.

[11] Strausak, D.; Mercer, J. F.; Dieter, H. H.; Stremmel, W.; Multhaup, G.; "Copper in disorder with neurological symptoms; Alzheimer's Menkes and Wilson disease"; Brain Res. Bull. 55, 175-185, 2001.

[12] Fallah, A. A.; Saei-Dehkordi, S. S.; Nematollahi, A.; Jafari, T.; "Comparative study of heavy metal and trace element accumulation in edible tissues of farmed and wild rainbow trout (Oncorhynchus mykiss) using ICP-OES technique"; Microchemical J. 98, 275-279, 2011.

[13] Hameed, T.; Asmat, T. M.; Tariq, M. M.; Bajwa, M. A.; Rafeeq, M.; Hilal, B.; Bokhari F. A.; "Study on current status and future trends of commercial poultry production in Pakistan"; Pure and Applied Biology 6, 190, 2017.

[14] Hussain, J.; Rabbani, I.; Aslam, S.; Ahmad, H. A.; "An overview of poultry industry in Pakistan"; World's Poul. Sci. J. 71, 689-700, 2015.
[15] Boskovic, M.; Baltic, M.; "Association between red meat consumption and cancer risk"; Sci. J. 57, 8188, 2016.

[16] Davis, G. S.; Waits, K.; Nordstrom, L.; Grande, H.; Weaver, B.; Papp, K.; Price, L. B.; "Antibioticresistant Escherichia coli from retail poultry meat with different antibiotic use claims"; BMC Microbiology 18, 174, 2018.

[17] Praveen, P. K.; Debnath, C.; Shekhar, S.; Dalai N.; Ganguly, S.; "Incidence of Aeromonas spp. infection in fish and chicken meat and its related public health hazards: A review"; Veter. World 9, 6, 2016.

[18] Zahir-ud-Din, M. F.; Durrani, F. R.; Chand, N.; Ahmed, J.; "Status of broilers produced in Swat, Pakistan”; Livestock Research for Rural Development 13, 67-71, 2001.

[19] Khan, M. Z.; Perween, S. H.; Gabol, K.; Khan, I. S.; Baig, N.; Kanwal, R.; Jabeen T.; "Concentrations of heavy metals in liver, meat and blood of poultry chicken Gallus domesticus in three selected cities of Pakistan”; Can. J. Pure Appl. Sci. 9, 3313-3324, 2015.

[20] Ei-Salam, N. M.; Ahmad, S.; Basir, A.; Rais, A. K.; Bibi, A.; Ullah, R.; Hussain, I.; "Distribution of heavy metals in the liver, kidney, heart, pancreas and meat of cow, buffalo, goat, sheep and chicken from Kohat market Pakistan"; Life Sci. J. 10, 937940, 2013.

[21] Mariam, I.; Iqbal, S.; Nagra, S.A.; "Distribution of some trace and macro minerals in beef, mutton and poultry"; Int. J. Agric. Biol. 6, 816-820, 2004.

[22] Imran, R.; Hamid, A.; Amjad, R.; "Estimation of the heavy metal concentration in the poultry meat being produced in Kasur"; J. Bio. and Env. Sci. 7, 62-75, 2015. 